Check for updates

Cite this: RSC Adv., 2018, 8, 7473

Received 11th January 2018

Accepted 3rd February 2018

DOI: 10.1039/c8ra00314a

rsc.li/rsc-advances

\section{Difference in the deactivation of Au catalysts during ethanol transformation when supported on $\mathrm{ZnO}$ and on $\mathrm{TiO}_{2} \dagger$}

\author{
M. V. Morales, ${ }^{a}$ E. Asedegbega-Nieto, (D) *a E. Castillejos-López, ${ }^{a}$ B. Bachiller-Baeza ${ }^{b}$ \\ and A. Guerrero-Ruiz (D)
}

\begin{abstract}
Au nanoparticles of different sizes were supported by the deposition-precipitation method on two metal oxides: $\mathrm{ZnO}$ and $\mathrm{TiO}_{2}$. The resulting catalysts were tested in the ethanol catalytic transformation reaction. Both metal oxide support materials exerted a different influence on the achieved Au particle size as well as on the behavior of the subsequent catalyst, with regard to their initial conversion values, product distribution and stability. While $\mathrm{TiO}_{2}$ favors the formation of smaller nanoparticles, $\mathrm{ZnO}$ offers larger $\mathrm{Au}$ particle sizes when prepared under similar conditions. At the same time, $\mathrm{TiO}_{2}$ produced catalysts which displayed higher initial conversions in comparison with AuZnO catalysts, even when observing catalysts of each series with similar particle sizes. At the same time, catalysts supported on $\mathrm{ZnO}$ exhibited higher resistance to deactivation caused by coke formation. These results were evidenced employing different characterization techniques on both used and fresh catalyst samples. The decline in deactivation was generally accompanied by an increase in the carbon content on the catalyst's surface.
\end{abstract}

\section{Introduction}

Oxidation, dehydration and dehydrogenation reactions involving ethanol are widely studied due to the valuable chemicals obtained in these processes..$^{1-3} \mathrm{An}$ important example is the dehydrogenation of ethanol to produce acetaldehyde which is an intermediate for the synthesis of higher C4 hydrocarbons. ${ }^{4}$ On the other hand, simple probe molecule reaction tests, such as ethanol transformation, aid in investigation purposes, looking into the behavior of catalysts in terms of the optimum nanoparticle size of the active phase, metal-support interaction, causes of deactivation, etc. ${ }^{5,6}$ Among the catalysts studied, the use of transition metal oxides has greatly increased the number of publications in this field when employed as supports or as active catalysts on their own. In this latter case, properties such as acid-base, redox and others, make these materials interesting candidates. Acid-base properties have been studied via various techniques such as chemisorption of probe molecules, microcalorimetry and IR spectroscopy, ${ }^{7,8}$ among others. Classification of metal oxides as strictly acidic or basic is not always straightforward. For example, $\mathrm{ZrO}_{2}$ and $\mathrm{TiO}_{2}$ are said to be significantly basic with medium to high Lewis and weak Brønsted acid sites. ${ }^{9-11}$ However, as is reported in these

${ }^{a}$ Department of Inorganic Chemistry and Chemical Engineering, UNED, Madrid, Spain. E-mail: easedegbega@ccia.uned.es

${ }^{b}$ Institute of Catalysis and Petrochemistry, CSIC, Madrid, Spain

† Electronic supplementary information (ESI) available. See DOI: 10.1039/c8ra00314a first two mentioned publications, these properties can be adjusted by combining with other metal oxides like $\mathrm{CeO}_{2}$ and $\mathrm{La}_{2} \mathrm{O}_{3}$. As for $\gamma$-alumina, it possesses various types of Lewis and Brønsted acid sites although its surface properties can be altered by doping with metal and metal oxides. ${ }^{12}$

Based on these characteristics, metal oxides have been studied in various ethanol based reactions. Zaki studied $\mathrm{Fe}_{2} \mathrm{O}_{3}$ and $\mathrm{Mn}_{2} \mathrm{O}_{3}$, among other oxides, in the ethanol dehydration reaction. ${ }^{13}$ Values of surface acidity, estimated by adsorption of pyridine (stronger acid sites) and piperidine (overall acidity), were intimately linked with the catalytic activity towards the dehydration products, ethylene and diethyl ether. In this referenced study, $\mathrm{Fe}_{2} \mathrm{O}_{3}$ and catalysts containing this metal oxide exhibited better behavior in comparison with $\mathrm{Mn}_{2} \mathrm{O}_{3}$ owing to its higher degree of strong acid sites. On the other hand, $\mathrm{Mn}_{2} \mathrm{O}_{3}$ has also been found suitable as an oxidative dehydrogenation catalyst, thanks to the presence of basic sites introduced by doping the oxide's framework with transition metals such as $\mathrm{Co}^{2+}$, obtaining over $80 \%$ selectivity towards acetaldehyde. ${ }^{14}$ As for the proper basic oxides such as $\mathrm{ZnO}$, $\mathrm{MgO}$, hidroxyapatites and their mixtures, these preferentially lead to the dehydrogenation products. ${ }^{15,16}$ Nevertheless, although basic sites are needed, it has been established that the selectivity towards acetaldehyde and further condensation products require the presence of acid-basic pairs. ${ }^{17}$ In this referenced publication, Di Cosimo et al. state that the $\mathrm{O}^{2-}$ anion of pure $\mathrm{MgO}$ is responsible for its strong basic sites and, although this basic property is necessary for the dehydrogenation pathway, an initial step involving ethoxide formation 
requires Lewis acid-strong base pairs. These authors achieved their goal of designing successful dehydrogenation catalysts, maintaining the strong basic sites of $\mathrm{MgO}$ and introducing the Lewis acid sites, by incorporation of $\mathrm{Al}$ in the optimal amount. Other authors have also obtained high dehydrogenation activities combining basic properties of one oxide with electronic or redox properties of another. Such is the case of noble metal free $\mathrm{ZnO}-\mathrm{CeO}_{2}$ catalyst, where the optimum proportion of $\mathrm{Zn} / \mathrm{Ce}$, on one hand, offers the right population of basic sites while, on the other hand, the $\mathrm{Ce}^{4+}$ to $\mathrm{Ce}^{3+}$ reduction is accompanied by the formation of oxygen vacancies, and as a whole, this catalysts yields higher activities. ${ }^{\mathbf{1 6}}$

Regarding the ethanol transformation reaction, apart from the product orientation aroused by the acidity or basicity of the transition metal oxide, the incorporation of metallic nanoparticles can also tune both activity and selectivity towards the desired products. Hence, the choice of the most adequate metal active site is very much appreciated. In this sense, various publications involve the use of supported noble metals. Idriss summarizes the results obtained in the study of ethanol reactions employing noble metals such as Pt, Pd, Rh and Au supported on ceria in a review. ${ }^{18}$ In his work, the difference in selectivity towards one or the other products is directly related to the characteristics of the active phase. For example, the addition, of the metals (in general) on ceria inhibits its selectivity towards the formation of acetates (oxidation of ethanol) whereas the dehydrogenation reaction towards acetaldehyde and its corresponding higher condensation products is enhanced by the introduction of Pt or Pd. Of all these noble metals, Rh exerted a singular behavior as it catalyzes the breaking of $\mathrm{C}-\mathrm{C}$ bond. Actually, this accused feature to readily dissociate $\mathrm{C}-\mathrm{C}$ bonds, makes $\mathrm{Rh}$ a suitable candidate for a variety of reactions involving ethanol such as steam reforming, ${ }^{19}$ oxidation, ${ }^{20}$ etc. since this $\mathrm{C}-\mathrm{C}$ cleavage is necessary prior to the production of $\mathrm{CO}_{2}$. In other works as that published by Gonçalves-Alonso et al., influence of the addition of noble metals, $\mathrm{Pd}$ and $\mathrm{Ru}$, on $\mathrm{Cu} / \mathrm{Nb}_{2} \mathrm{O}_{5}$ were studied in the ethanol reforming reaction. ${ }^{21}$ In this reaction it is known that hydrogen formation occurs mainly via dehydrogenation reaction where acetaldehyde formation is the first step involved. The addition of $\mathrm{Ru}$ and $\mathrm{Pd}$ not only enhance the activity and selectivity towards the dehydrogenation route, respectively, but also decreased the deactivation behavior of the un-modified $\mathrm{Cu}$ / $\mathrm{Nb}_{2} \mathrm{O}_{5}$ catalyst.

Among the noble metals, gold is becoming a first choice in several reactions owing to its extraordinarily high activity under relatively mild conditions. ${ }^{22}$ Its efficiency in catalysis can be questioned owing to the fact that it is the most noble metal known, however on the contrary it has been proven otherwise. An example is in the acetylene hydrodechlorination reaction. ${ }^{23}$ In this publication, gold is reported to have superior behavior not in activity but more importantly because it is exclusively selective to the desired product, vinyl chloride monomer, while the appearance of byproducts is suppressed. Various studies focus on the unique catalytic properties of gold. An important parameter to be highlighted is the particle size of $\mathrm{Au}$ nanoparticles employed. It is known that its singularity lies in the unsaturated surface atoms which would be enhanced when coordinated in small clusters. In fact, it is a proven point that particles must not be larger than $5 \mathrm{~nm} .^{\mathbf{2 4 , 2 5}}$ For this reason, various studies focus on new synthesis methods or routes to produce small and well dispersed Au nanoparticles. This can be achieved by encapsulation in zeolites, ${ }^{26}$ thiolate-protection of metal nanoclusters,${ }^{27}$ incorporation of additives,${ }^{28}$ etc. In this latter reference, additives such as Ce and La adjust the structural and electronic properties of the support and hence affect $\mathrm{Au}$ nanoparticle size distribution. Other approaches such as speciation-controlled incipient wetness impregnation (ScIWI) take into account calculated thermodynamic species distribution diagrams as well as synthesis controlling parameters, such as $\mathrm{pH}$, producing Au nanoparticles as small as $1 \mathrm{~nm} .^{29}$

The right combination of metal active phase and support is crucial to the catalytic behavior of the catalyst. Titania supported gold catalysts exert catalytic activity under milder conditions than with supports such as alumina or silica. ${ }^{30,31}$ Very recently, J. Quesada et al. analyzed the role of Au nanoparticles supported on $\mathrm{TiO}_{2}$ in the ethanol condensation reaction obtaining improved results, when compared to the bare support, in particular as refers to dehydrogenation activities. ${ }^{32}$ As was previously mentioned, when employed without incorporation of metal phase, metal oxides have also shown catalytic activity. For the partial oxidation of ethanol to acetaldehyde, $\mathrm{TiO}_{2}$ gave highest activity results at lowest reaction temperature when compared with $\mathrm{Al}_{2} \mathrm{O}_{3}$, SBA-15 (mesoporous $\mathrm{SiO}_{2}$ ) or hydrotalcite. ${ }^{33}$ On other oxides such as $\gamma-\mathrm{Al}_{2} \mathrm{O}_{3}$, the Lewis acid sites are said to be responsible for the dehydration of ethanol where ethylene is formed through the unimolecular pathway or diethyl ether through the bimolecular route. ${ }^{34}$ A. Gazsi et al. ${ }^{6}$ carried out a comparative study of ethanol adsorption and decomposition employing catalysts based on $\mathrm{Au}$ supported on various materials $\left(\mathrm{Al}_{2} \mathrm{O}_{3}, \mathrm{CeO}_{2}, \mathrm{TiO}_{2}, \mathrm{SiO}_{2}, \mathrm{MgO}\right.$, and Norit) of different acid-base and redox properties. Results obtained in their work gave insights to the role of Au as well as the influence of the different supports employed. In general, supported $\mathrm{Au}$ nanoparticles were active for the catalytic dehydrogenation of ethanol. On one hand, Au was said to enhance the formation of the ethoxy species, monitored by TPD and DRIFTS experiments, especially when supported on $\mathrm{SiO}_{2}$. On the other hand, $\mathrm{Au} /$ $\mathrm{Al}_{2} \mathrm{O}_{3}$, gave highest selectivity towards dehydration products. As far as the deactivation of catalysts is concerned, $\mathrm{CeO}_{2}$ supported Au catalyst presented the best behavior. The lack of deactivation in this case was said to be due to the interface between $\mathrm{Au}$ and the partially reduced support.

In this contribution, the results obtained in the catalytic transformation reaction of ethanol over Au NPs supported on $\mathrm{ZnO}$ tetrapods and on a commercial $\mathrm{TiO}_{2}$ are presented. Both supports were chosen owing to their different unique properties in terms of acidity, reducibility, structure, morphology, etc. which would definitely exert different influence on the resulting catalysts. We present a synthetic route for the design of highperformance $\mathrm{Au}$ catalyst by deposition-precipitation. A comparative study is carried out between both series of supported catalysts employing different characterization techniques. The synthesis, structure-property correlation, and the 
relative activity of the systems are presented, focusing on the influence of the size of gold nanoparticles and their interaction with the support on the catalytic activity.

\section{Experimental procedure}

\section{Preparation of supported gold catalysts}

Commercial $\mathrm{TiO}_{2}$ (P25) supplied by Sigma Aldrich (BET surface area 35-65 $\mathrm{m}^{2} \mathrm{~g}^{-1}$ ) and $\mathrm{ZnO}$ tetrapods (henceforth denoted as $\mathrm{ZnO}$ ) were employed as supports. Synthesis of $\mathrm{ZnO}$ tetrapods $\left(12-28 \mathrm{~m}^{2} \mathrm{~g}^{-1}\right)$ were carried out by chemical vapor deposition as reported elsewhere. ${ }^{35}$ Deposition-precipitation method was used in order to synthesize the gold catalysts. A solution of $\mathrm{HAuCl}_{4} \cdot 3 \mathrm{H}_{2} \mathrm{O}$ (purchased from Sigma Aldrich) in a mixture water/methanol (15/1) was added to the selected metal oxide support. After ultrasonic treatment at $283 \mathrm{~K}$ for 5 minutes, it was treated with an aqueous solution of $\mathrm{NaOH}(0.2 \mathrm{M})$ until $\mathrm{pH}=$ 11. Then, the precipitate was stirred in an iced bath to obtain small nanoparticles (defined as -a), at room temperature to produce medium sized particles (defined as -b) or at $313 \mathrm{~K}$ to achieve particles of larger dimensions (defined as -c). This procedure lasted $5 \mathrm{~h}$ and thereafter the resulting samples were collected by filtration. Finally, the precipitate was washed with deionized hot water, until no $\mathrm{Cl}^{-}$was detected. The sample was dried overnight at $373 \mathrm{~K}$ in air. The corresponding catalysts were

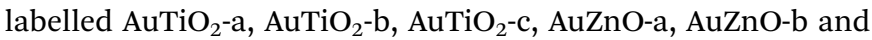
AuZnO-c. These samples were subjected to a pretreatment in flowing $\mathrm{N}_{2}$ at $573 \mathrm{~K}$ for $1 \mathrm{~h}$ previous to the dehydrogenation reaction tests.

\section{Instrumentation and measurements}

All the samples (both catalysts and supports) were characterized prior to and after reaction by X-ray photoelectron spectroscopy (XPS), X-ray diffraction (XRD), diffuse reflectance infrared Fourier transform spectroscopy (DRIFTS), transmission electron microscopy (TEM) and thermogravimetric analysis coupled to mass spectrometry (TGA-MS).

XPS analysis was performed with an ESCA-PROBE P (Omicron) spectrometer by using nonmonochromatized $\mathrm{Mg}-\mathrm{K} \alpha$ radiation $(1253.6 \mathrm{eV})$. TEM micrographs were obtained from a JEOL JEM-2100F microscope at $200 \mathrm{kV}$. The mean diameter of the $\mathrm{Au}$ particles was calculated, based on a minimum of 100 particles, using the following formula: $d_{\mathrm{Au}}=\sum n_{i} d_{i} / \sum n_{i}$, being $n_{i}$ the number of particles with a diameter of $d_{i}$. Infrared spectra were obtained at room temperature on a FT-IR (Varian 670) spectrometer. XRD patterns were obtained on a Polycristal X'Pert Pro PANalytical diffractometer with Ni-filtered $\mathrm{Cu} / \mathrm{K} \alpha$ radiation $(\lambda=0.1544 \mathrm{~nm}$ ) operating at $45 \mathrm{kV}$ and $40 \mathrm{~mA}$. For each sample, Bragg's angles between $4^{\circ}$ and $90^{\circ}$ were scanned at a rate of $0.04 \mathrm{deg} \mathrm{\textrm {s } ^ { - 1 }}$. Thermogravimetric analyses were carried out in an SDT Q 600 apparatus on used catalysts under inert atmosphere (He $100 \mathrm{~mL} \mathrm{~min}^{-1}$ ) and in order to study evolution of desorbed products the TGA equipment was coupled with a quadruple mass spectrometer (Pfeiffer Vacuum Omnistar ${ }^{\mathrm{TM}}$ GSD 301). For this purpose, the following mass fragments were recorded taking into account the corresponding literature: ${ }^{36} \mathrm{H}_{2}$ $(\mathrm{m} / \mathrm{z}=2), \mathrm{CO}(\mathrm{m} / \mathrm{z}=28$ and 16$), \mathrm{CO}_{2}(\mathrm{~m} / \mathrm{z}=44), \mathrm{H}_{2} \mathrm{O}(\mathrm{m} / \mathrm{z}=18$ and 17), ethanol $(\mathrm{m} / \mathrm{z}=31,29,45$ and 27$)$, acetaldehyde $(\mathrm{m} / \mathrm{z}=$ 29, 44, 43 and 15), diethyl ether $(\mathrm{m} / \mathrm{z}=31,59,74$ and 45), ethylene $(\mathrm{m} / \mathrm{z}=28,27$ and 26$)$, butene $(\mathrm{m} / \mathrm{z}=41$ and 56), crotonaldehyde $(\mathrm{m} / \mathrm{z}=41,39,70$ and 69$)$, butanal $(\mathrm{m} / \mathrm{z}=44,43,72$, 41, 27 and 29), ethyl acetate $(\mathrm{m} / z=43), 2$-butenol $(\mathrm{m} / \mathrm{z}=57$ and $29)$, benzene $(\mathrm{m} / \mathrm{z}=78$ and 77$)$, butanone $(\mathrm{m} / \mathrm{z}=43$ and 72$)$ and furan $(\mathrm{m} / \mathrm{z}=68$ and 39$)$. In cases where the most intense $\mathrm{m} / \mathrm{z}$ signal was coincident in more than one specie, a secondary less intense signal had to be taken into account. The Au loading was determined employing inductively coupled plasma mass spectrometry (ICP-MS).

\section{Catalytic test}

Catalytic conversion of ethanol reactions were carried out at atmospheric pressure. In each test, $50 \mathrm{mg}$ of catalyst diluted in glass beads were loaded in a glass tube $(9 \mathrm{~mm}$ id) that served as a fixed-bed, continuous flow reactor. $15 \mu \mathrm{L} \mathrm{min}{ }^{-1}$ of ethanol (99.8\% purity) were diluted in helium (total flow rate of 20 $\mathrm{mL} \mathrm{min}^{-1}$ ) and passed through the catalytic bed. At regular time intervals the reaction products were analyzed in a gas chromatograph (GC) apparatus, equipped with both TCD and FID detectors. This analysis system is directly coupled to the reactor exit. The identification of reaction products was achieved bearing in mind the retention times of pure reference standards. When present, peaks corresponding to unknown condensation products (trace amounts) were integrated using the response factor of butanol. The transformation reaction of ethanol was studied at $573 \mathrm{~K}$ during 400 minutes. Conversion $\left(X_{\text {EтоH }}\right)$ and selectivity $(S)$ were estimated employing the following equations:

$$
X_{\mathrm{ETOH}}=\frac{\left[C_{\mathrm{ETOH}}\right]_{\text {in }}-\left[C_{\mathrm{ETOH}}\right]_{\mathrm{out}}}{\left[C_{\mathrm{ETOH}}\right]_{\text {in }}} \times 100 \%
$$

where $\left[C_{\mathrm{ETOH}}\right]_{\text {in }}$ and $\left[C_{\mathrm{ETOH}}\right]_{\text {out }}$ represent the total ethanol concentration in the inlet and outlet gas, respectively.

$$
S_{i}=\frac{\left[n_{i} C_{i}\right]}{\sum_{i}\left[n_{i} C_{i}\right]} \times 100 \%
$$

where $n_{i}$ and $C_{i}$ are the number of carbon atoms and concentration of the product $(i)$, respectively.

TOF was also calculated considering the number of moles of ethanol converted per surface atom per second. For this, the number of active sites at the surface of the catalyst was deduced from XPS analysis as has been done in other publications. ${ }^{37}$

$$
\mathrm{TOF}=\frac{\text { converted ethanol }\left(\mathrm{mol} \mathrm{s}{ }^{-1}\right)}{\text { active sites number }(\mathrm{mol})}
$$

\section{Results}

\section{Catalysts characteristics prior to the reaction}

Information on the degree of crystallinity and phase were obtained from XRD diffractograms. Fig. S1 (view ESI $\dagger$ ) exhibits patterns of support as well as resulting catalysts. Peaks observed 


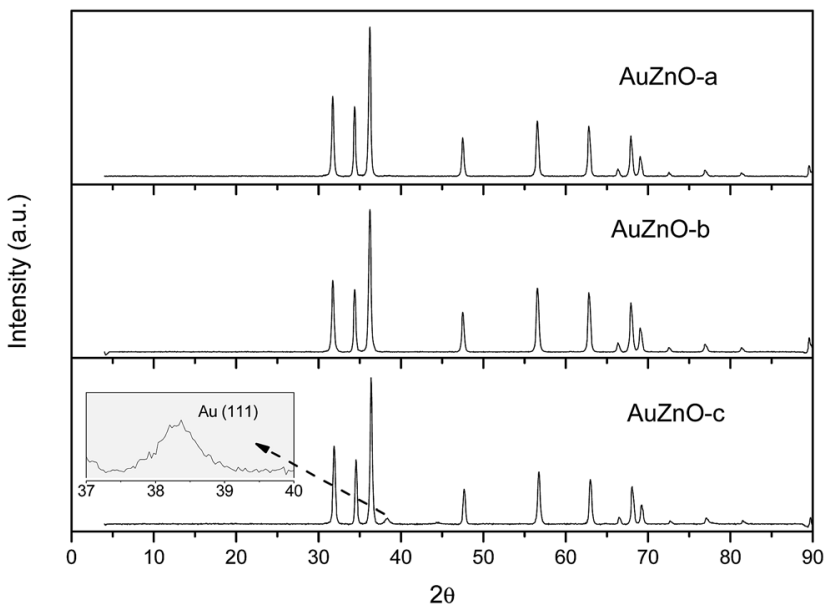

Fig. 1 XRD diffractograms of AuZnO catalysts.

in the $\mathrm{TiO}_{2}$ support material belong to rutile and anatase phases in the relative ratio of $76 \%: 24 \%$ which is similar to literature findings for this type of commercial supports where ratios of $75 \%: 25 \%$ are generally observed. ${ }^{38}$ On the other hand, the contribution of other phases such as brookite phase was not observed. The incorporation of $\mathrm{Au}$ nanoparticles made no apparent changes in the XRD pattern of the resulting catalysts when compared with that of the $\mathrm{TiO}_{2}$ support.

As for the $\mathrm{ZnO}$ series all $\mathrm{Au} / \mathrm{ZnO}$ catalysts displayed peaks of ZnO wurtzite phase (JCPDS-36-1451). ${ }^{39}$ Apart from these peaks owing to the support, in certain samples, peaks around 38.3, 44.5 and $64.5^{\circ}$ were also visible owing to the diffraction planes (111), (200) and (220), respectively, of Au nanoparticles (JCPDS04-0784). ${ }^{40}$ This is particularly visible in sample AuZnO-c (Fig. 1) while the other two samples displayed the same XRD patterns as the initial $\mathrm{ZnO}$ support. Hence, the former has larger particle sizes.

TEM images as well as size distribution histograms of the $\mathrm{TiO}_{2}$ series are depicted in Fig. 2. When employing this support, sizes of 2.2, 3.4 and $5.2 \mathrm{~nm}$ were obtained as a consequence of the different temperatures employed in each case during catalyst synthesis. These particles are too small to be detected by $\mathrm{XRD}$ as was corroborated by the absence of $\mathrm{Au}$ (111) peaks at about $38^{\circ}$. As refers to the particle size distribution, $\mathrm{AuTiO}_{2}$ a exhibits a narrower distribution in comparison with $\mathrm{AuTiO}_{2}$ b and especially with $\mathrm{AuTiO}_{2}$-c where sizes of up to $11 \mathrm{~nm}$ are observed.

Fig. 3 displays the TEM results for the $\mathrm{ZnO}$ series and in agreement with XRD patterns the following order of particle sizes was found: AuZnO-a $<$ AuZnO-b $<$ AuZnO-c. One can easily deduce that this support favors the formation of larger nanoparticles with respect to the $\mathrm{TiO}_{2}$ material. The presence of some tetrapods of $\mathrm{ZnO}$ formed from nanorods is clearly visible (insert in Fig. 3 AuZnO-c). These structures have a diameter ranging from $8-40 \mathrm{~nm}$ and lengths of $100 \mathrm{~nm}$ to $1 \mathrm{~mm}$. In this series a wider distribution of $\mathrm{Au}$ NPs sizes is observed in comparison with the $\mathrm{TiO}_{2}$ series.

XPS analyses gave further insights as refers to surface composition of samples. As was expected, the gold surface composition detected in the fresh catalysts is in line with the degree of dispersion observed in TEM images, i.e., smaller particles give rise to higher surface percentage revealed by XPS. When expressed in terms of $\mathrm{wt} \%$. values range from above $7 \%$ for $\mathrm{AuTiO}_{2}$-a to below 2\% for $\mathrm{AuTiO}_{2}$-c also hinting on the variation of degree of dispersion for all samples of similar metal loading of around $2 \%$ as was determined by ICP-MS measurements. As refers to the binding energies, the envelope of the $\mathrm{Au}$ $4 \mathrm{f}_{7 / 2}$ peak had a maximum at about $83.4 \mathrm{eV}$ which is a bit lower


Fig. 2 TEM micrographs and particle size histograms of $\mathrm{TiO}_{2}$ supported Au catalysts. 

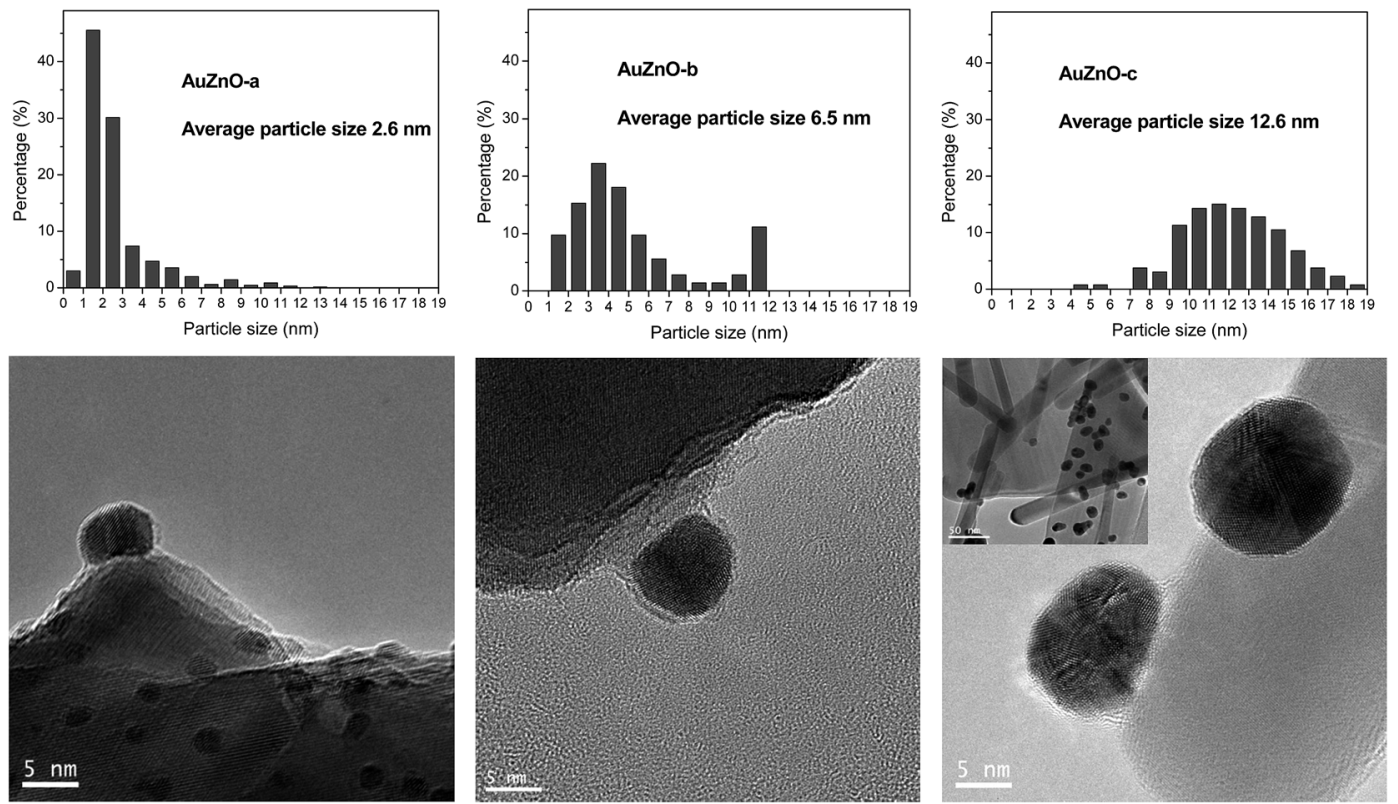

Fig. 3 TEM images and particle size histogram of AuZnO-a, AuZnO-b and AuZnO-c.

than that normally observed for Au (0) implying the possibility of interaction between support and nanoparticles. At the same time, apart from the presence of metallic gold, there is a smaller contribution at about $84.9 \mathrm{eV}$ (17\% atomic) owing to the presence of $\mathrm{Au}(\mathrm{I})$. Similar results were obtained by Ousmane et al. where $15 \%$ of $\mathrm{Au}(\mathrm{I})$ was observed. ${ }^{41}$ It was said that in these catalysts composed of Au supported on titania, part of the $\mathrm{Au}(\mathrm{I})$ component would likely diffuse at the interface with the $\mathrm{TiO}_{2}$ support, thereby maintaining its oxidation state even after reaction. The deconvolution of the envelope into the two components of one of the $\mathrm{AuTiO}_{2}$ catalysts can be viewed in Fig. 4(a).

In the case of $\mathrm{ZnO}$ catalysts, surface atomic composition of $\mathrm{Au}$ expressed as $\mathrm{wt} \%$ is about $4.5 \%$ (for samples of smallest $\mathrm{Au}$ NPs size) of the total catalysts mass which is higher than that obtained by ICP-MS $(\sim 2 \%)$ owing to the small particles

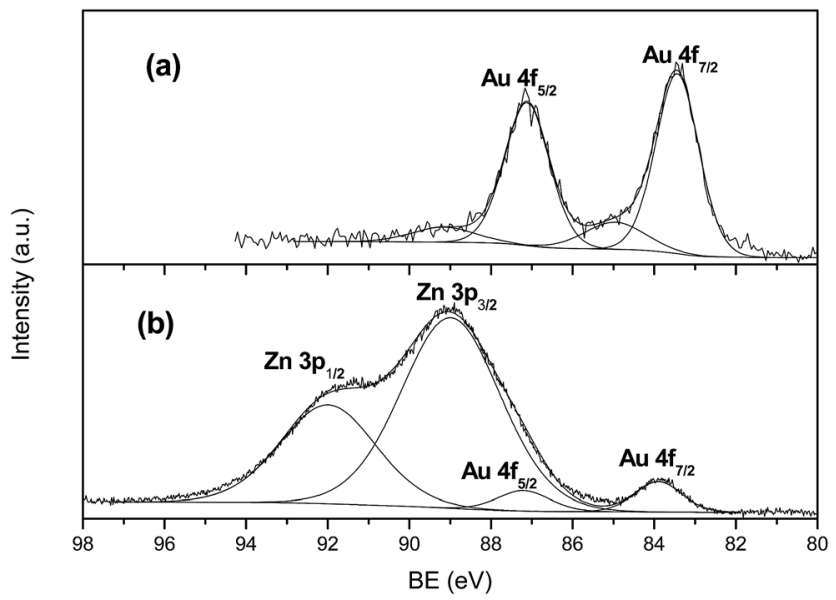

Fig. 4 XPS spectra of Au $4 f$ for (a) $\mathrm{AuTiO}_{2}-\mathrm{a}$ and (b) AuZnO-a. deposited at the surface of the metal oxide and hence its high dispersion. On the other hand, for these series of catalyst, $\mathrm{Au}$ $4 \mathrm{f}_{7 / 2}$ peak appeared close to $84 \mathrm{eV}$ (Fig. 4(b)). This value is typical of metallic gold and is in agreement with studies employing samples of similar characteristics. ${ }^{40}$

\section{Catalytic test}

The catalytic transformation of ethanol carried out at $573 \mathrm{~K}$ during 400 minutes was studied with both series of catalysts. In all cases activity, selectivity towards reaction products and stability of catalysts were evaluated. Blank experiments involving supports without $\mathrm{Au}$ nanoparticles were also conducted. In Fig. 5 conversion versus reaction time is represented for the two series. Commercial $\mathrm{TiO}_{2}$ material exhibited a rather low activity. Conversion values were below 3\% during all 400 minutes of reaction. The bare $\mathrm{ZnO}$ support was also tested and conversion was equally low (about 4\%) at the temperature studied. As for the titania-supported $\mathrm{Au}$ catalyst, conversion values were significantly higher in all catalysts of this series than that of the bare support. Scalbert et $a{ }^{15}$ studied the possible reaction routes of transformation of ethanol to butanol and stated that the presence of metal, in bi-functional solids, reduced the reaction temperature when compared with metal free catalyst. A main difference is in the hydrogenation step where hydrogen atoms are involved in the former while for the latter, it is more likely to occur via hydrogen transfer between two molecular species.

Initial conversion in this work refers to values after 5 minutes on stream. These initial conversion values follow the order: $\mathrm{AuTiO}_{2}-\mathrm{a}>\mathrm{AuTiO}_{2}-\mathrm{b}>\mathrm{AuTiO}_{2}$-c, and keeping in mind the particle size estimated by TEM, as was mentioned above, these results suggest that activity is inversely proportional to particle size, i.e., smaller nanoparticles yield higher conversion values, 

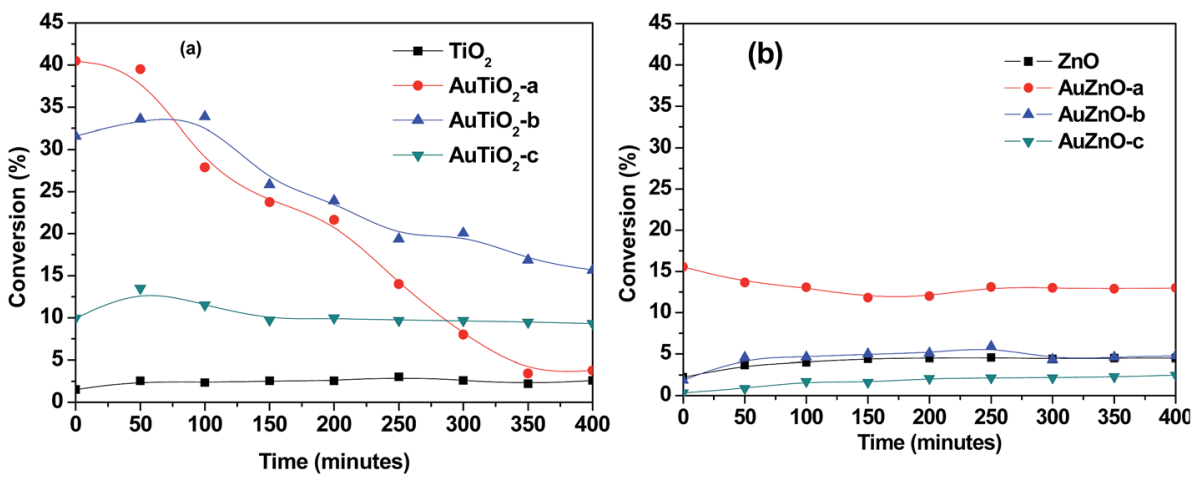

Fig. 5 Conversion versus time for studied catalysts ( $T=573 \mathrm{~K})$.

which is consistent with a higher exposed surface area of active metallic sites. Surprisingly enough, some authors highlighted that the optimal catalytic activity of $\mathrm{Au} / \mathrm{SiO}_{2}$ catalysts was found for Au nanoparticles of about $6 \mathrm{~nm}$ which exhibited higher conversion in the ethanol dehydrogenation reaction than the smaller or larger ones. ${ }^{5}$ Also Zheng and Stucky found higher conversions in the ethanol oxidation for the medium particle size of $6.3 \mathrm{~nm}$, in comparison with the larger $(8.2 \mathrm{~nm})$ or the smaller $(3.5 \mathrm{~nm}) \mathrm{Au}$ nanoparticles supported on $\mathrm{SiO}_{2} \cdot{ }^{42}$ However, in our work, $\mathrm{TiO}_{2}$ supported Au nanoparticles of small size (either $\mathrm{AuTiO}_{2}$-a or $\mathrm{AuTiO}_{2}$-b) display significantly higher conversion in comparison with the $5.2 \mathrm{~nm}$ ones $\left(\mathrm{AuTiO}_{2}-\mathrm{c}\right)$. On the other hand, catalyst deactivation follows the opposite direction. The catalyst with smallest $\mathrm{Au}$ nanoparticles, $\mathrm{AuTiO}_{2}$-a, rapidly deactivates ( $\sim 90 \%$ deactivation) while that of largest particles, $\mathrm{AuTiO}_{2}$-c, maintains its conversion practically constant ( $\sim 7 \%$ deactivation). As for $\mathrm{AuTiO}_{2}-\mathrm{b}$, the obtained conversion slightly increases during the first $100 \mathrm{~min}$ on stream and then it stars to decrease with a rate which is intermediate between the two extremes ( $\sim 50 \%$ deactivation). In other words, the smaller the Au particle size, the higher its deactivation rate, as a consequence of the higher conversion levels achieved from early stages of the reaction. This results in a change in conversion values at the end of the 400 minutes duration of experiments, as can be viewed from Fig. 5, where conversion has an new order: $\mathrm{AuTiO}_{2}-\mathrm{b}>\mathrm{AuTiO}_{2}-\mathrm{c}>$ $\mathrm{AuTiO}_{2}$-a. It is worth to note that carbon balances decrease until values close to $70 \%$ in this series of catalysts which suggests the possible retention of reaction products at the catalysts surface, as will be discussed later.

As for the catalytic behavior of the ZnO series, two main differences can be highlighted when compared with the $\mathrm{TiO}_{2}$

Table 1 Average particle size and TOF values of studied catalysts

\begin{tabular}{lll}
\hline Sample & Particle size nm (TEM) & TOF $\left(\mathrm{s}^{-1}\right)$ \\
\hline AuTiO $_{2}$-a & 2.2 & 0.088 \\
AuTiO $_{2}$-b & 3.4 & 0.164 \\
AuTiO $_{2}$-c & 5.2 & 0.084 \\
AuZnO-a & 2.6 & 0.054 \\
AuZnO-b & 6.5 & - \\
AuZnO-c & 12.6 & -
\end{tabular}

series. In the first place, stability over 400 minutes of reaction is much higher as can be seen in Fig. 5 where deactivation is much lower in (b) than in (a). In second place, initial conversion values are considerably lower for the ZnO series (Fig. 5(b)). In this case, owing to their lower activity and taking into account the larger particle sizes obtained in general, in some cases the conversion of the supported catalyst is lower than that of the support on its own. It is known that for $\mathrm{Au}$ to act as good catalysts particle sizes have to be below $5 \mathrm{~nm}^{.24}$ Therefore it could be fully understood why AuZnO-c (12.6 nm) has lower conversion values than $\mathrm{ZnO}$. Here, AuZnO-c is not only inactive but also its presence reduces the exposed surface of the support thereby reducing its reactivity.

When comparing two samples of similar Au nanoparticle size and metal loading of $\sim 2 \%\left(\right.$ AuTiO $_{2}$-a and AuZnO-a) the differences in conversion levels are quite obvious. While $\mathrm{AuTiO}_{2}$-a $(2.2 \mathrm{~nm})$ offers initial values of $40 \%$, thereafter diminishing to $\sim 5 \%$, AuZnO-a $(2.6 \mathrm{~nm})$ with initial conversion value of $15.6 \%$ reduces until $13 \%$. The differences between both catalysts can be attributed to the influence of the support on the catalytic activity. On one hand, and generally speaking, $\mathrm{TiO}_{2}$ favors the formation of smaller gold nanoparticles with respect to $\mathrm{ZnO}$. On the other hand, catalysts of similar particle sizes belonging to the two series exhibit different catalytic behavior.

Initial TOF values were estimated for all catalysts with conversions above those of their corresponding supports and of particle sizes $\leq 5 \mathrm{~nm}$. Therefore, AuZnO-b and AuZnO-c were discarded as their activity is below or almost the same as that of $\mathrm{ZnO}$ and nanoparticles were above $5 \mathrm{~nm}$. For this same reason and as has been stated earlier, the complete characterization study of these two catalysts was not conducted or included in the corresponding section. The estimated values are given in Table 1, where the following order was observed: $\mathrm{AuTiO}_{2}$-b > $\mathrm{AuTiO}_{2}$-a $>\mathrm{AuTiO}_{2}$-c $>$ AuZnO-a. AuTiO size, $3.4 \mathrm{~nm}$, is the catalysts that offered best results doubling that of the $\mathrm{AuTiO}_{2}$-a which presented higher initial conversion values whereas this latter of smaller particle size $(2.2 \mathrm{~nm})$ tends to deactivate more rapidly. Of all four catalysts, that supported on $\mathrm{ZnO}$ offers the lowest TOF value and the formation of successive condensation products is greatly reduced.

Product distribution was also studied. Selectivity at early stages of the reaction as well as after 400 minutes on stream is 
depicted in Fig. 6. The main product obtained with the bare $\mathrm{TiO}_{2}$ support was the acid-catalyzed dehydration product diethyl ether, followed by acetaldehyde, ethylene and butene. This should be expected as $\mathrm{TiO}_{2}$ is said to be an amphoteric oxide exhibiting medium and strong Lewis acid sites, weak Brønsted acid sites and a few weakly basic sites. ${ }^{11}$ Significant changes are observed with the introduction of $\mathrm{Au}$ in the catalysts. In general terms, acetaldehyde is the main product while the formation of diethyl ether has been greatly reduced agreeing with literature findings. ${ }^{43}$ This is most significant when employing catalysts of smaller Au nanoparticles, where values of about $70 \%$ (acetaldehyde selectivity) are observed. As can be seen in Fig. 6, for catalysts with smaller Au sizes, crotonaldehyde, originated through the base-catalyzed aldol condensation mechanism from acetaldehyde, is the second most important product after this latter although its value reduces drastically over the 400 minutes reaction period. Other secondary products detected (C4 alcohols and butanal) are also involved in the Guerbet reaction mechanism from ethanol. ${ }^{44}$ As was mentioned earlier, samples with smallest $\mathrm{Au}$ particle sizes $\left(\mathrm{AuTiO}_{2}-\mathrm{a}\right)$ experience severe deactivation behavior. Hence, at lower conversion values, subsequent condensation products are not likely to form. As for samples that exhibited lower initial activity and greater stability, product distribution is less distorted.

As for the $\mathrm{ZnO}$ series, acetaldehyde is by far the main product observed (above 80\%) with the bare support and in contrast to $\mathrm{TiO}_{2}$ support the presence of diethyl ether, which was its primary product, was not detected. In our previous work, we studied a series of $\mathrm{ZnO}$ materials of different morphologies and surface functionalities. ${ }^{45}$ In all cases, the dehydrogenation product, acetaldehyde, was obtained with selectivity values of $84-94 \%$. The formation of this primary product was said to involve the presence of acid-basic pairs on the surface of the catalyst. In our actual work, the $\mathrm{ZnO}$ support also favors the formation of acetaldehyde while subsequent condensation products such as crotonaldehyde and ethyl acetate (from the dimerization of acetaldehyde or direct dehydrogenation of ethanol $^{46}$ ) are just about 1 and $5 \%$, respectively. At the same time, ethylene, the dehydration product owing to the acidic properties of this material is present in about 5\%. Very little variations are observed during the 400 minutes of reaction. It should be noted that at the end of the reaction, there is an increase in ethyl acetate at the expense of acetaldehyde which has reduced from 88 to $84 \%$. For all three Au supported $\mathrm{ZnO}$ catalysts employed in the catalytic test, acetaldehyde was the main product with selectivity values of over $95 \%$ in all cases at the initial stages of the reaction. Hence, the incorporation of $\mathrm{Au}$ favored the dehydrogenation reaction pathway in comparison with the bare support. On the other hand, selectivity towards ethylene is below 5\%. Evolution of main product, acetaldehyde, towards secondary products such as ethyl acetate, crotonaldehyde and 1-butanol (or 2-butenol) was observed during the 400 minutes of reaction studied at $573 \mathrm{~K}$ (Fig. 6(c and d)).

\section{Catalysts characteristics after reaction}

XRD measurements performed on catalysts after reaction were similar to those obtained with the fresh catalysts, indicating no apparent sintering of Au NPs under the reaction conditions, and for the sake of brevity the diffractograms are not included in this manuscript but in the ESI section (Fig. S1-c $\dagger$ ).

Infrared spectroscopy can reveal valuable information concerning the presence of surface carbonaceous species on deactivated catalysts. ${ }^{47,48}$ DRIFTS measurements were carried out
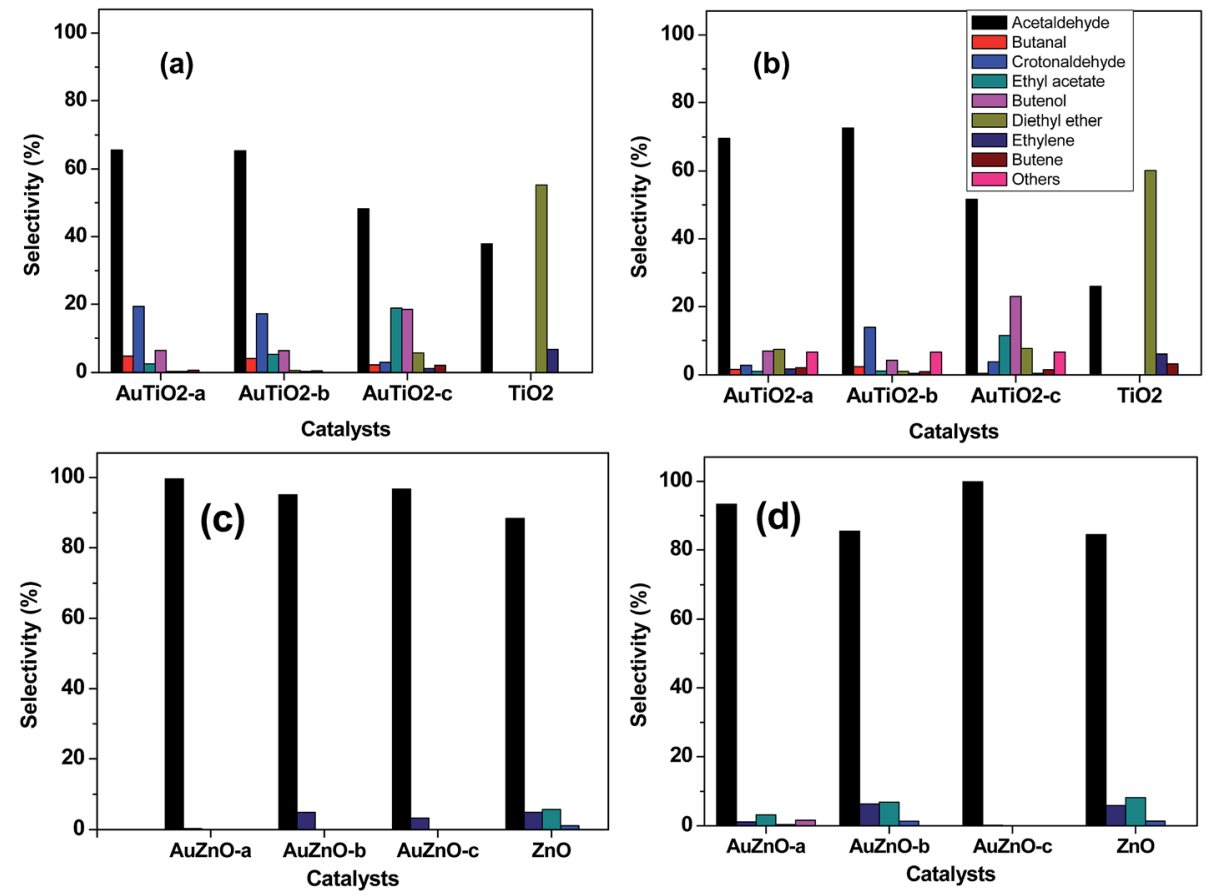

Fig. 6 Product distribution at initial ((a) and (c)) and after 400 minutes ((b) and (d)) of reaction for AuTiO ${ }_{2}$ series and AuZnO series ( $\left.T=573 \mathrm{~K}\right)$. 
before and after reaction and differences between both spectra were analyzed. Besides the studied catalysts, DRIFTS experiments were also performed on support materials. The spectrum of $\mathrm{TiO}_{2}$ is included in Fig. S2. $\dagger$ According to the literature, ${ }^{49}$ the broad band from about 3380 to $3400 \mathrm{~cm}^{-1}$ can be ascribed to the stretching vibration of water molecules. This is further confirmed by the presence of a peak at about $1600 \mathrm{~cm}^{-1}$ owing to the bending vibration of the $\mathrm{O}-\mathrm{H}$ group. This latter contribution also corresponds to the presence of Ti-O groups of titania based samples which in addition exhibit bands around 800-1000 $\mathrm{cm}^{-1}$ due to Ti-O-Ti vibrations. Similar peaks were observed in the fresh $\mathrm{Au}-\mathrm{TiO}_{2}$ catalysts.

As for the used catalysts, significant differences can be found when compared with their former spectra. Fig. 7 displays the spectrum of $\mathrm{AuTiO}_{2}$-a and AuZnO-a catalysts (prior to and after reaction), where the presence of coke can be identified by the typical bands of hydrocarbon molecules in the most important regions at $2850-3000 \mathrm{~cm}^{-1}$ and $1700-1300 \mathrm{~cm}^{-1}$. The rest spectra of $\mathrm{AuTiO}_{2}$ materials are depicted in Fig. S2 (ESI $\dagger$ ). The bands in the region of $2850-3000 \mathrm{~cm}^{-1}$ correspond to aliphatic (asymmetric and antisymmetric stretching) ${ }^{50}$ and single-ring aromatics. ${ }^{47,48}$ Distinctive bands at 2958 and $2870 \mathrm{~cm}^{-1}$ of $\mathrm{CH}_{3}$ groups appeared, together with the characteristics bands of $-\mathrm{CH}_{2}$ and $-\mathrm{CH}$ groups at 2930, 2900 and $2855 \mathrm{~cm}^{-1}$. Also, distinctive bands at 1377 and $1443 \mathrm{~cm}^{-1}$ corresponding to $\mathrm{CH}_{3}$ symmetric and antisymmetric deformation, ${ }^{\mathbf{5 0 , 5 1}}$ respectively, appeared. This suggests that carbonaceous species could consist of aliphatic hydrocarbons or unsaturated naphthenes. ${ }^{48}$

Bands in the region 1700-1300 $\mathrm{cm}^{-1}$ include molecular vibrations that can be ascribed to different functional groups (Fig. 7). The presence of acetate species can be deduced by the 1456 and 1513 bands, due to -COO- symmetric and antisymmetric stretching, respectively. ${ }^{52}$ Spectral characteristic features of acetaldehyde at $1691 \mathrm{~cm}^{-1} \nu(\mathrm{C}=\mathrm{O})$ was also found in the used catalysts. Characteristic bands of the condensation product crotonaldehyde appeared at 1658 and $1634 \mathrm{~cm}^{-1} .^{53}$ It is

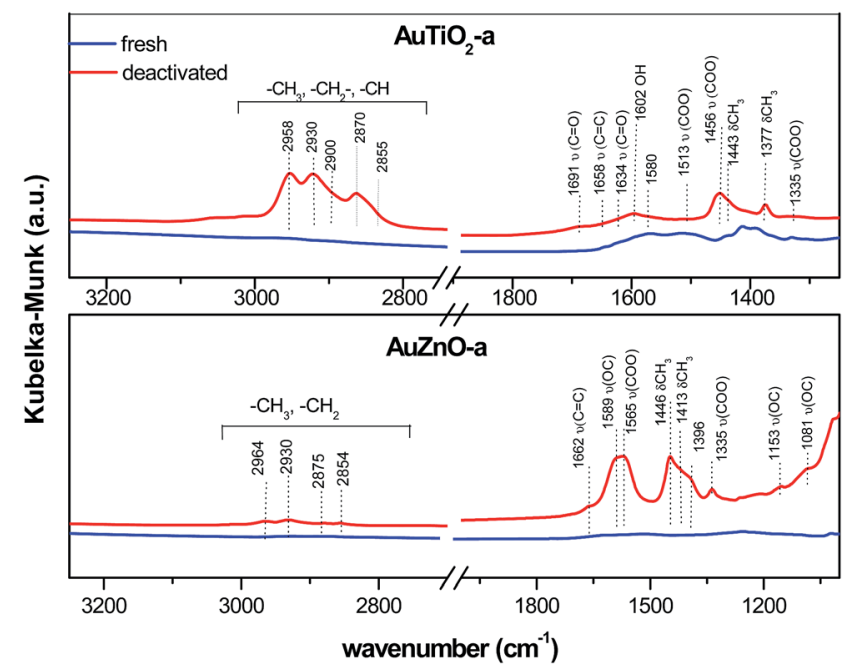

Fig. 7 DRIFT spectra of fresh and used $\mathrm{AuTiO}_{2}-\mathrm{a}$ and AuZnOa catalysts. worth to note that the presence of these peaks was most pronounced in samples with smaller $\mathrm{Au}$ nanoparticles (Fig. S2†).

DRIFTS measurements were also performed on the $\mathrm{ZnO}$ based samples. For comparison reasons a spectra of a catalyst belonging to this series, AuZnO-a (prior to and after the reaction) is included in Fig. 7. Measurements of AuZnO-b and AuZnO-c were not included in Fig. S2 $\uparrow$ owing to the large particle sizes determined by TEM, which as was earlier discussed in the corresponding section, did not have relevant influence on the catalytic activity. As can be observed, differences detected in this studied series differ from that of $\mathrm{TiO}_{2}$ based samples. On one hand, bands in the 2980 to $2850 \mathrm{~cm}^{-1}$ range owing to $\nu \mathrm{CH}_{3}$ mode of aliphatic hydrocarbons ${ }^{54}$ have also increased in the used samples when compared with the corresponding fresh ones although in this case the increase is much smaller than was observed for the $\mathrm{TiO}_{2}$ series. Nevertheless, and in this set of samples, as can be seen in Fig. 7, this region includes four bands at about 2964, 2930, 2875 and $2854 \mathrm{~cm}^{-1}$, and together with those found at lower frequencies (1153 and $1081 \mathrm{~cm}^{-1}$ ), are said to correspond to ethoxy species adsorbed on $\mathrm{ZnO}$ supported catalysts. ${ }^{55}$ On the other hand, the relative ratio of bands owing to the presence of surface oxygenates (e.g. $\left.\nu \mathrm{CO}\left(\sim 1589 \mathrm{~cm}^{-1}\right)\right)$ to $-\mathrm{CH}$ groups $\left(e . g . \delta \mathrm{CH}_{3}\left(\sim 1446 \mathrm{~cm}^{-1}\right)\right)$ for used samples is higher than in the case of $\mathrm{TiO}_{2}$ supported samples. Bands at about $1565 \mathrm{~cm}^{-1}$ could be ascribed to the acetate species obtained from the dehydrogenation of ethoxy species. ${ }^{55,56}$ No apparent changes between fresh and used samples are observed in the $\nu \mathrm{OH}$ band at about $3560-3670 \mathrm{~cm}^{-1}$ region which corresponds to the surface hydroxyl groups of $\mathrm{ZnO}$ (Fig. S2 $\dagger){ }^{57}$

XPS analyses gave further insights as refers to surface composition of samples before and after reaction. Table 2 summarizes atomic percentages of $\mathrm{Au}$ before and after reaction. These XPS results can also be visualized in Fig. S3 (ESI $\dagger$ ) where, as can be observed, $\mathrm{C}$ 1s significantly increased after reaction at the expense of the other components (Au, Ti and O). The ratio of $\mathrm{Au}$ to metal oxide support reduces for the catalyst of smallest particle size, $\mathrm{AuTiO}_{2}$-a, due to the carbon species which are deposited both on the gold and metal oxide support. Table 2 also includes the values of the ratio (used with respect to fresh) of atomic \% of carbon content. From this data one can observe how catalysts with smaller particles retain higher carbon components. These results are in agreement with those obtained by DRIFTS.

Table 2 XPS surface atomic composition of fresh and used catalysts

\begin{tabular}{|c|c|c|c|}
\hline \multirow[b]{2}{*}{ Sample } & \multirow{2}{*}{$\frac{\text { Fresh }}{\mathrm{Au}(\text { at \%) }}$} & \multirow{2}{*}{$\frac{\text { Used }}{\text { Au (at \%) }}$} & \multirow{2}{*}{$\begin{array}{l}\text { Increase in carbon deposits: } \\
\text { used with respect to fresh } \\
\left(\mathrm{C}_{\mathrm{used}} / \mathrm{C}_{\text {fresh }}\right)\end{array}$} \\
\hline & & & \\
\hline $\mathrm{AuTiO}_{2}$-a & 0.82 & 0.2 & 2.80 \\
\hline $\mathrm{AuTiO}_{2}$-b & 0.33 & 0.09 & 2.91 \\
\hline $\mathrm{AuTiO}_{2}-\mathrm{c}$ & 0.19 & 0.20 & 1.31 \\
\hline AuZnO-a & 0.49 & 0.42 & 1.10 \\
\hline
\end{tabular}



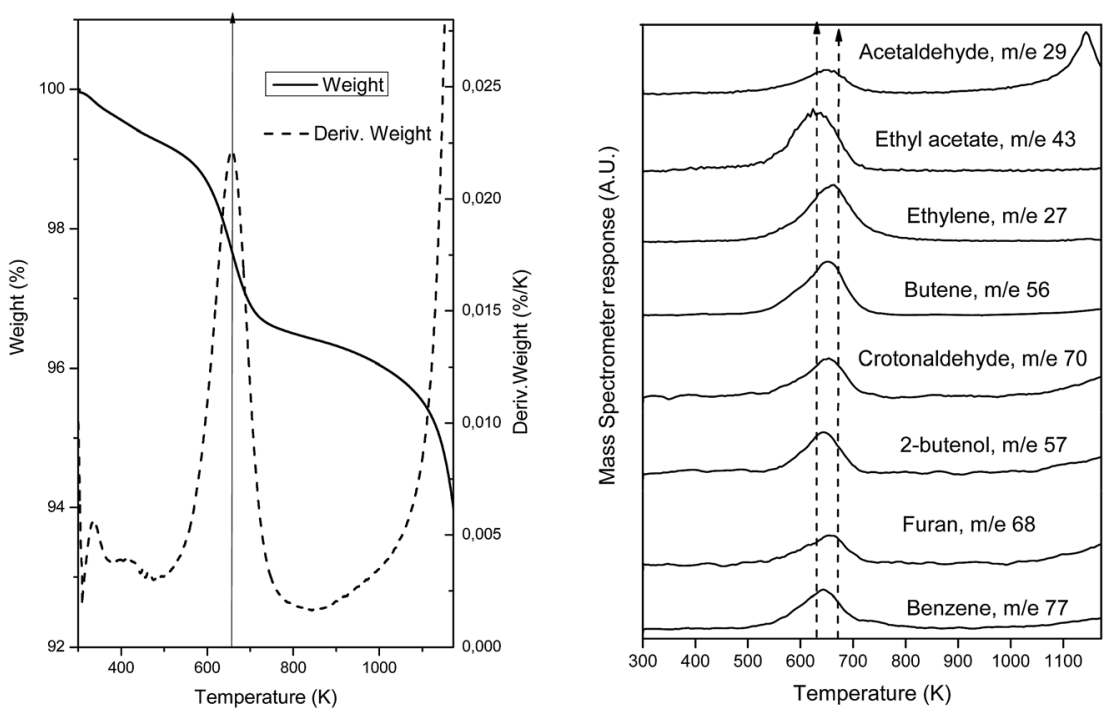

Fig. 8 TGA-MS of $\mathrm{AuTiO}_{2}$-a showing desorbed species of used catalyst.

As refers to XPS analyses, results for the AuZnO catalysts were quite different from those obtained for $\mathrm{AuTiO}_{2}$. A quick view at Table 1 and Fig. $\mathrm{S} 3, \dagger$ highlights these differences. In this case, surface atomic composition of Au doesn't seem to vary much while the increase in $\mathrm{C}$ atomic ratio at the surface of samples after reaction is insignificant.

To further confirm and identify the type of carbon deposits present on the surface of spent catalysts, desorption of adsorbed species was followed by TGA-MS on the used samples. For this, samples were heated until $1173 \mathrm{~K}$ at a rate of $5 \mathrm{~K} \mathrm{~min}^{-1}$ under a $100 \mathrm{~mL} \min ^{-1}$ flow of He (TGA) and the products evolved were followed by mass spectrometry (MS). Fig. 8(a) presents the weight loss experimented due to the desorption of the carbon products formed during the reaction while Fig. 8(b) shows the mass fragments desorbed during this heating process for the sample which presents most drastic changes after reaction, $\mathrm{AuTiO}_{2}$-a. Weight loss $(\sim 3 \%)$ is observed at about $658 \mathrm{~K}$ as can be deduced from the thermogravimetric analysis profile. This temperature value is coincident and is within the maxima observed, between 630 and $672 \mathrm{~K}$, of the desorbed species detected by mass spectrometry (Fig. 8(b)). As can be viewed, the mass fragments corresponding to the following carbon compounds were found: acetaldehyde, ethylene, butene, crotonaldehyde, ethyl acetate, 2-butenol, butanol, furan and benzene. In our catalytic tests we did not identify these latter two aromatic compounds, which suggests that they remain adsorbed at the catalyst surface. Nadeem et al. ${ }^{24}$ also detected these aromatic compounds when studying the reactions of ethanol by TPD and IR spectroscopy on the surface of $\mathrm{AuTiO}_{2}$ catalysts. They proposed the reaction mechanism formation of benzene over $\mathrm{AuTiO}_{2}$ catalysts as follows: adsorbed crotonaldehyde and acetaldehyde react yielding 2,4-hexadienal; thereafter, $\mathrm{Au}$ nanoparticles break the $\mathrm{C}-\mathrm{H}$ bond of the methyl group which after intramolecular cyclisation followed by $\mathrm{H}_{2} \mathrm{O}$ elimination may give benzene.
In our study, MS results are not presented to scale, and so serve only for qualitative and not quantitative purposes. The existence of all these species confirms DRIFTS and XPS analyses results, proving that the presence of carbon products adsorbed on the surface reduces/blocks the area of active sites exposed and this could interfere with the catalytic activity as observed in the catalytic test section of this work.

Desorption study of carbonaceous compounds was also followed by this same TGA-MS analysis for the ZnO series and in this case, it is worth to highlight that the weight loss in this catalyst is less than $1 \%$ wt confirming the lower quantity of coke deposits in comparison with $\mathrm{AuTiO}_{2}$ catalysts ( $\sim 3.5 \%$ wt loss). Mass fragments corresponding to ethanol, acetaldehyde, ethyl acetate, ethylene and diethyl ether, were observed. This last listed product (diethyl ether) was not observed within the products analysed by GC during the catalytic test, but may be present in trace concentration or may have remained adsorbed at the catalyst surface, which would be coincident with the ethoxy species observed by DRIFTS. In general terms, these results differ from that obtained in the $\mathrm{TiO}_{2}$ series where heavier condensation products (furan and benzene), were retained at the catalysts surface. All this would be further highlighted in the following section.

\section{Discussion}

Our results indicate that the deactivation observed on the $\mathrm{TiO}_{2}$ series is due to the deposition of carbonaceous species formed during the reaction and strongly adhered to the surface of the catalyst which results in activity loss due to the blockage of active sites. XPS analyses results as well as DRIFTS corroborated this explanation. This was further confirmed by TGA-MS, where the type of deposits desorbed from the surface can be related to the selectivity towards the different products obtained during the catalytic test. Recalling from the previous section, for series $\mathrm{TiO}_{2}$, acetaldehyde, ethylene, butene, crotonaldehyde, ethyl 
acetate, 2-butenol, benzene, furan and butanol were observed whose presence on the surface reduces the area of active sites exposed thereby diminishing the catalytic activity and causing deactivation. As for the $\mathrm{ZnO}$ series, desorption of the following carbon deposits: ethanol, acetaldehyde, diethyl ether, ethyl acetate and ethylene, were observed. The absence of higher condensation products (butane, furan and benzene) in this series is evident and marks the difference between both series. At this point, one could state that, the mass fragments observed in this desorption study are in agreement with the selectivity mainly towards primary reaction products determined for the ZnO catalysts which don't seem to lead to high deactivation.

Taking into consideration results obtained so far as refers to extent of reaction reached as confirmed by the catalytic test, products found at the catalyst surface as was revealed by TGAMS experiments and IR bands observed in the DRIFTS experiments, Fig. 9 was designed. In this illustration where all these results are combined, one catalyst of each series (of similar particle size) is presented in order to detect differences. Various remarks can be made on viewing both graphs. On one hand, there are significant differences in terms of product distribution and IR bands between both graphs. On the other hand, these IR bands match perfectly with the products predicted in each case. Some of the bands identifying the products desorbed are marked highlighting the concurrence found on combining the characterization and catalytic tests results obtained as well as the differences observed between both samples. Once more, we can confirm that higher conversion and therefore presence of a higher quantity of condensation products as well as heavier products are reached with $\mathrm{TiO}_{2}$ supported $\mathrm{Au}$ catalysts when compared with the $\mathrm{ZnO}$ catalysts of similar particle size. However, carbon deposits on $\mathrm{ZnO}$ catalysts consist of lighter physisorbed byproducts (diethyl ether, ethyl acetate, etc.), and the absence of condensed aromatic compounds avoid severe deactivation.

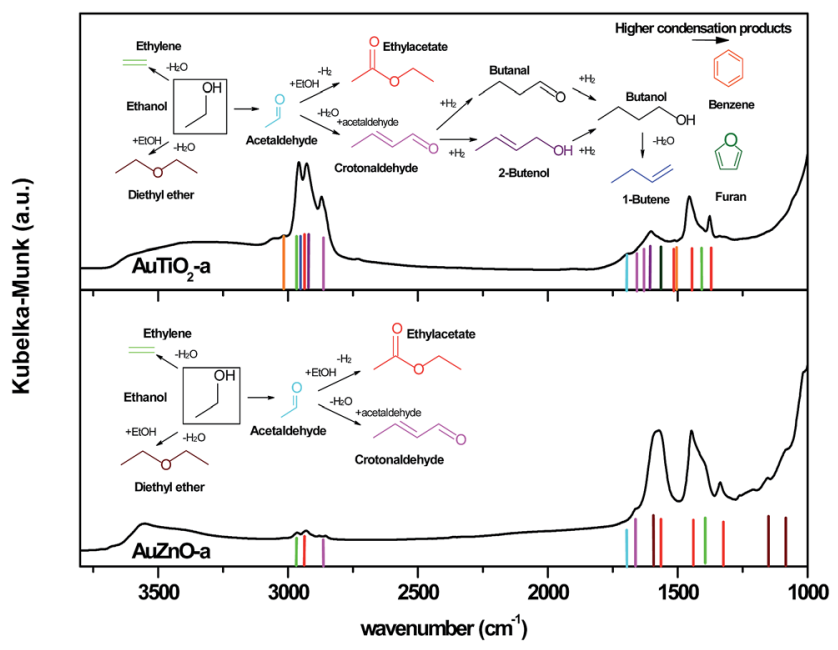

Fig. 9 DRIFTS spectra of the two supported Au catalysts of similar particle size after reaction and identification of possible products adsorbed at the catalysts surface.
Now, coming back to the fact that two catalysts of very similar particle size $\left(\right.$ AuTiO $_{2}$-a: 2.2 and AuZnO-a: $\left.2.6 \mathrm{~nm}\right)$ and metal loading (about 2\% wt) would exhibit such different behavior in this catalytic test, as refers to conversion and product distribution, deserves additional discussion. As a matter of fact, it can only be attributed to their sole difference, the corresponding metal oxide supports. The support could exert influence in many ways without discarding any of its inherent properties such as specific surface area, redox or acidbase properties. Related to this latter are the $\mathrm{pH}_{\mathrm{PZC}}$ values which are reported to be 6.4 (ref. 58) and between 8.7-9.7 (ref. 59 ) at room temperature, for $\mathrm{TiO}_{2}$ and $\mathrm{ZnO}$, respectively. The differences in the acid-base properties of the metal oxides, apart from causing effects on the deposition of the metal active phase would also participate in the selectivity towards the reaction products obtained as these supports also exhibit catalytic activity on their own. This is clearly visible on comparing the selectivity results depicted in Fig. 6 where while $\mathrm{TiO}_{2}$ was predominantly selective towards diethyl ether, acetaldehyde was the main product obtained with $\mathrm{ZnO}$ bare support. This has also been supported by literature where it is said that $\mathrm{TiO}_{2}$ offers higher selectivity towards diethyl ether in comparison to other oxides due to the fact that the stronger interaction between the reactant and surface leads to preferential formation of this product by the reaction between two molecules of ethanol. ${ }^{32}$ Likewise, in a previous study performed by our research group, acid and basic sites of $\mathrm{ZnO}$ materials were characterized by the isopropanol reaction test and confirmed that this material exposes mainly basic sites. This would explain the higher selectivity to the dehydrogenation product, acetaldehyde. At the same time, the formation of the byproduct, ethylene was conditioned by the presence of a specific type of acidic hydroxyl group located at the base surfaces of $\mathrm{ZnO}^{45}$ Nevertheless, based on the significantly higher activity of noble metal compared with the bare support when employed as catalyst as we aforementioned, the support on its own would not cause these significant differences but rather would orient the differences observed in the resulting $\mathrm{Au}$ NPs deposition and therefore on the characteristics of this active phase exposed and responsible for the catalytic activity. In the previously cited ref. 32, the presence of Au changes the selectivity pattern of the $\mathrm{TiO}_{2}$ support due to its role promoting the ethanol dehydrogenation to acetaldehyde, and also favoring the hydrogen transfer step of aldol condensation product (view reaction scheme presented in Fig. 9) thereby resulting in the formation of $\mathrm{C} 4$ alcohols. This is in line with our obtained results. As for those of the $\mathrm{ZnO}$ series, the selectivity pattern was not changed with respect to that of the bare support but rather catalysts of very small nanoparticle sizes gave improved conversion values while the dehydrogenation product, acetaldehyde remained the most the principally obtained. Therefore, we cannot rule out the part played by nature of the support on the catalytic activity and selectivity of the active sites. This is clearly observed in our case where $\mathrm{Au}$ of similar particle sizes behaved so differently.

On the other hand, various studies involving Au NPs have pointed out the importance of strong metal-support 
interactions (SMSI) ${ }^{60-62}$ In a work published by Menegazzo et al. it was demonstrated how the properties of the support were decisive in the gold dispersion, position and shape. ${ }^{63}$ This was achieved by introducing sulphates on the $\mathrm{ZrO}_{2}$ surface. Their presence oriented the deposition of Au NPs in positions other than the corners and edges which were occupied by the sulphate groups. In another study of Akita et al., an atomic-scale structure investigation on the interface between $\mathrm{Au}(\mathrm{III})$ and $\gamma$ $\mathrm{Fe}_{2} \mathrm{O}_{3}$ was carried out by microscopy techniques and a preferential orientation relationship was observed between both materials. ${ }^{64}$ In our case, the differences in shapes and deposition sites could be induced by the characteristics of the two different metal oxides employed as support ( $\mathrm{TiO}_{2}$ and $\left.\mathrm{ZnO}\right)$. In a review article titled "Catalysis by gold: new insights into the support effect" emphasis is paid on the part played by the support in shaping the resulting supported Au NPs. ${ }^{65}$ Among other features discussed, the influence of reducibility of the metal oxide support is questioned. According to this review, $\mathrm{TiO}_{2}$ is considered under the category of reducible supports and tend to provide more favorable conditions for higher dispersion of hemispherically shaped NPs due to the stronger metalsupport interaction. The consequent increase in interface between both materials is also said to be beneficial to catalytic activity. On the other hand, with irreducible oxides such as $\mathrm{ZnO}$, lower interaction with the NPs is expected and thus, and although the presence of defects could cause modifications, spherically shaped particles are more likely to be formed. However, in a study carried out employing $\mathrm{ZnO}$ of different origins as support for Au NPs, it was said that in contrast to commercial nanocrystalline $\mathrm{ZnO}$ which allowed the deposition of more spherical particles, an epitaxial relation existed between the noble metal and the support when this latter was $\mathrm{ZnO}$ tetrapods. ${ }^{66}$ This enhanced its catalytic activity when compared to other $\mathrm{ZnO}$ conventional supports in the preferential oxidation reaction of carbon monoxide under hydrogen rich conditions. Nevertheless, and due to this epitaxial phenomenon, the interplanar distances of Au changed and lead to strain which was more accused for smaller particles causing the adverse effect of dractically reducing its catalytic performance.

From the above mentioned we can deduce that in our case, both supports would offer interaction with the $\mathrm{Au}$ particles but based on our results, it seems like the effects of this interactions would be more pronounced for those based on $\mathrm{TiO}_{2}$. This could be further confirmed taking into account characterization results previously discussed in the corresponding section where some $\mathrm{Au}^{1+}$ was detected (by XPS) in the $\mathrm{TiO}_{2}$ supported $\mathrm{Au}$ catalysts. This was not the case for the $\mathrm{ZnO}$ series. The oxidized gold species are said to diffuse at the interface between both materials. ${ }^{41}$ In addition, steps, corners and edges are known to be adsorbing sites in $\mathrm{Au}$ nanoparticles for certain molecules ${ }^{67}$ and the fraction of these sites would also be a consequence of the size and shape of Au NPs. All these could be applicable to our study where, the different shapes or positions obtained in both cases would explain why with one material higher activity and adsorption of certain reaction products is favored thereby leading to its deactivation. In other words, the selectivity and specially the catalytic activity of supported gold catalysts for the transformation reaction of ethanol could be controlled by tuning the size and morphology (degree of particle rounding and flattening, proportion of multiply twinned particles, number of steps, corners and edges, etc.) of the NPs as a consequence of the support chosen.

\section{Conclusions}

Our obtained results indicate that the catalytic properties of $\mathrm{Au}$ supported catalysts are strongly influenced by the support employed (type of metal oxide) and Au NP size (tuned during catalyst preparation). On one hand, within the same series of catalysts, Au nanoparticle size can be controlled by changing the synthesis temperature. When comparing both series of catalysts it is proved that $\mathrm{TiO}_{2}$ supported catalysts offered smaller particles and at the same time exhibited significantly higher initial conversion values, although these later decreased drastically especially in samples of smallest particle sizes. ZnO supported samples have more moderate initial conversions and in all cases deactivations were hardly observed even for samples with sizes as small as $2.6 \mathrm{~nm}$. On the other hand, when comparing samples of similar particle size of each series, although in both cases the presence of gold facilitates the formation of acetaldehyde by dehydrogenation of ethanol, significant differences were clearly observed in terms of activity and product distribution. This fact proves the key role played by the support in the catalytic transformation of ethanol. The deactivation process has been evidenced (DRIFTS, XPS, TGAMS) to be related to the presence of coke on the catalyst surface, inhibiting the activity. These carbon species consists of oxygenated hydrocarbons and aromatic compounds, the presence of the latter is more pronounced on the $\mathrm{TiO}_{2}$ supported samples, which explain the higher deactivation rate exhibited by these catalysts in comparison with the $\mathrm{ZnO}$ supported ones.

\section{Conflicts of interest}

There are no conflicts to declare.

\section{Acknowledgements}

We acknowledge financial support from the Spanish Government (CTQ2014-52956-C3-2-R and -3-R, CTQ2017-89443-C3-1-R and $-3-\mathrm{R}$ projects). MVM is grateful to the UNED for a predoctoral grant.

\section{References}

1 M. Zhang and Y. Yu, Ind. Eng. Chem. Res., 2013, 52, 9505.

2 D. Fan, D.-J. Dai and H.-S. Wu, Materials, 2013, 6, 101.

3 E. V. Makshina, M. Dusselier, W. Janssens, J. Degrève, P. A. Jacobs and B. F. Sels, Chem. Soc. Rev., 2014, 43, 7917.

4 J. H. Earley, R. A. Bourne, M. J. Watson and M. Poliakoff, Green Chem., 2015, 17, 3018.

5 Y. Guan and E. J. M. Hensen, Appl. Catal., A, 2009, 361, 49. 6 A. Gazsi, A. Koos, T. Bansagi and F. Solymosi, Catal. Today, 2011, 160, 70. 
7 V. Bolis, G. Cerrato, G. Magnacca and C. Morterra, Thermochim. Acta, 1998, 312, 63.

8 L. Ferretto and A. Glisenti, Chem. Mater., 2003, 15, 1181.

9 D. Stošić, S. Bennici, S. Sirotin, P. Stelmachowski, J.-L. Couturier, J.-L. Dubois, A. Travert and A. Auroux, Catal. Today, 2014, 226, 167.

10 D. Stošić, S. Bennici, J.-L. Couturier, J.-L. Dubois and A. Auroux, Catal. Commun., 2012, 17, 23-28.

11 N. Bou-Orm, A. Iorgu, S. Daniele and N. Guilhaume, Appl. Catal., A, 2013, 467, 414.

12 J. H. Kwak, J. Lee, J. Szanyi and C. H. F. Peden, Catal. Today, 2016, 265, 240.

13 T. Zaki, J. Colloid Interface Sci., 2005, 284, 606.

14 H. Zhou, J. Y. Wang, X. Chen, C.-L. O'Young and S. L. Suib, Microporous Mesoporous Mater., 1998, 21, 315.

15 J. Scalbert, F. Thibault-Starzyk, R. Jacquot, D. Morvan and F. Meunier, J. Catal., 2014, 311, 28.

16 N. Enjamuri, S. Hassan, A. Auroux, J. K. Pandey and B. Chowdhury, Appl. Catal., A, 2016, 523, 21.

17 J. I. Di Cosimo, V. K. Diez, M. Xu, E. Iglesia and C. R. Apesteguia, J. Catal., 1998, 178, 499.

18 H. Idriss, Platinum Met. Rev., 2004, 48, 105.

19 P. Osorio-Vargas, C. H. Campos, R. M. Navarro, J. L. G. Fierro and P. Reyes, Appl. Catal., A, 2015, 505, 159.

20 S. Y. Shen, T. S. Zhao and J. B. Xu, Int. J. Hydrogen Energy, 2010, 35, 12911.

21 C. Gonçalves Alonso, A. C. Furtado, M. Pereira Cantão, O. Aparecida Andreo dos Santos and N. Regina Camargo Fernandes-Machado, Int. J. Hydrogen Energy, 2009, 34, 3333.

22 J. Fang, B. Zhang, Q. Yao, Y. Yang, J. Xie and N. Yan, Coord. Chem. Rev., 2016, 322, 1.

23 P. Johnston, N. Carthey and G. J. Hutchings, J. Am. Chem. Soc., 2015, 137, 14548.

24 A. M. Nadeem, G. I. N. Waterhouse and H. Idriss, Catal. Today, 2012, 182, 16.

25 W. Huang, in Heterogeneous Gold Catalysts and Catalysis, ed. Z. Ma and S. Dai, The Royal Society of Chemistry, Cambridge, UK, 2014, ch. 15, pp. 533-574.

26 T. Otto, S. I. Zones and E. Iglesia, J. Catal., 2016, 339, 195.

27 J. Fang, J. Li, B. Zhang, X. Yuan, H. Asakura, T. Tanaka, K. Teramura, J. Xie and N. Yan, Nanoscale, 2015, 7, 6325.

28 Y. Kotolevich, E. Kolobova, E. Khramov, M. H. Farías, Ya. Zubavichus, H. Tiznado, S. Martınez-Gonzalez, V. Cortes Corberan, J. D. Mota-Morales, A. Pestryakov and N. Bogdanchikova, J. Mol. Catal. A: Chem., 2017, 427, 1.

29 E. del Río, D. Gaona, J. C. Hernández-Garrido, J. J. Calvino, M. G. Basallote, M. J. Fernández-Trujillo, J. A. Pérez-Omil and J. M. Gatica, J. Catal., 2014, 318, 119.

30 V. I. Sobelev, O. A. Simakova and K. Y. Koltunov, ChemCatChem, 2011, 3, 1422.

31 V. I. Sobelev, K. Y. Koltunov, O. A. Simakova, A.-R. Leino and D. Y. Murzin, Appl. Catal., A, 2012, 433-434, 88.

32 J. Quesada, R. Arreola-Sanchez, L. Faba, E. Diaz, V. M. Renteria-Tapia and S. Ordoñez, Appl. Catal., A, 2018, 551, 23.

33 J. M. Hidalgoa, Z. Tislera, D. Kubickaa, K. Raabovab and R. Bulanek, J. Mol. Catal. A: Chem., 2016, 420, 178.
34 J. F. DeWilde, C. J. Czopinski and A. Bhan, ACS Catal., 2014, $4,4425$.

35 R. Bacsa, J. Dexpert-Ghys, M. Verelst, A. Falqui, B. Machado, W. S. Bacsa, P. Chen, S. M. Zakeeruddin, M. Graetzel and P. Serp, Adv. Funct. Mater., 2009, 19, 875.

36 NIST Chemistry WebBook, NIST Standard Reference Database Number 69, http://webbook.nist.gov/chemistry/, accessed July 2016.

37 Z. Ren, Y. Guo, Z. Zhang, C. Liua and P.-X. Gao, J. Mater. Chem. A, 2013, 1, 9897.

38 M. Nasir Khan and J. Bashir, J. Mod. Phys., 2011, 2, 962.

39 L. Guo, Y. L. Ji, H. Xu, P. Simon and Z. Wu, J. Am. Chem. Soc., 2002, 124, 14864.

40 E. Castillejos, E. Gallegos-Suarez, B. Bachiller-Baeza, R. Bacsa, P. Serp, A. Guerrero-Ruiz and I. RodríguezRamos, Catal. Commun., 2012, 22, 79.

41 M. Ousmane, L. F. Liotta, G. Pantaleo, A. M. Venezia, G. Di Carlo, M. Aouine, L. Retailleau and A. Giroir-Fendler, Catal. Today, 2011, 176, 7.

42 N. Zheng and G. D. Stucky, J. Am. Chem. Soc., 2006, 128, 14278.

43 M. C. Holz, K. Tölle and M. Muhler, Catal. Sci. Technol., 2014, 4, 3495.

44 D. Gabriëls, W. Y. Hernández, B. Sels, P. Van Der Voort and A. Verberckmoes, Catal. Sci. Technol., 2015, 5, 3876.

45 M. V. Morales, E. Asedegbega-Nieto, A. Iglesias-Juez, I. Rodriguez-Ramos and A. Guerrero-Ruiz, ChemSusChem, 2015, 8, 2223.

46 E. Santacesaria, G. Carotenuto, R. Tesser and M. Di Serio, Chem. Eng. J., 2012, 179, 209.

47 P. Castaño, G. Elordi, M. Olazar, A. T. Aguayo, B. Pawelec and J. Bilbao, Appl. Catal., B, 2011, 104, 91.

48 Y. Li, C. Zhang, Y. Liu, S. Tang, G. Chen, R. Zhang and X. Tang, Fuel, 2017, 189, 23.

49 R. Fiorenza, M. Bellardita, L. Palmisano and S. Scirè, J. Mol. Catal. A: Chem., 2016, 415, 56.

50 D. Lin-Vien, N. Colthup, W. Fateley and J. Grasselli, The Handbook of Infrared and Raman Characteristic Frequencies of Organic Molecules, Academic Press, 1991, ISBN: 978-0-12451160-6.

51 H. De Paz-Simon, A. Chemtob, C. Croutxé-Barghorn, S. Rigolet, L. Michelin, L. Vidal and B. Lebeau, Langmuir, 2013, 29, 1963.

52 R. Kydd, W. Y. Teoh, J. Scott, D. Ferri and R. Amal, ChemCatChem, 2009, 1, 286.

53 A. Yee, S. J. Morrison and H. Idriss, J. Catal., 2000, 191, 30. 54 C. Drouilly, J.-M. Krafft, F. Averseng, H. Lauron-Pernot, D. Bazer-Bachi, C. Chizallet, V. Lecocq and G. Costentin, Catal. Today, 2013, 205, 67.

55 R. Yang, Y. Fu, Y. Zhang and N. Tsubaki, J. Catal., 2004, 228, 23.

56 R. Yang, Y. Zhang and N. Tsubaki, Catal. Commun., 2007, 8, 1829.

57 J. Llorca, N. Homs and P. Ramirez de la Piscina, J. Catal., 2004, 227, 556.

58 N. Kallay, T. Madić, K. Kučej and T. Preočanin, Colloids Surf., A, 2003, 230, 3. 
59 C. B. Tay, S. J. Chua and K. P. Loh, J. Cryst. Growth, 2009, 311, 1278.

60 A. A. Herzing, C. J. Kiely, A. F. Carley, P. Landon and G. J. Hutchings, Science, 2008, 321, 1331.

61 Z. Wang, H. Fu, Z. Tian, D. Hana and F. Gu, Nanoscale, 2016, 8, 5865.

62 P. H. Rana and P. A. Parikh, J. Ind. Eng. Chem., 2017, 47, 228.
63 F. Menegazzo, M. Signoretto, D. Marchese, F. Pinna and M. Manzoli, J. Catal., 2015, 326, 1.

64 T. Akita, Y. Maeda and M. Kohyama, J. Catal., 2015, 324, 127. 65 X. Y. Liu, A. Wang, T. Zhang and C.-Y. Mou, Nano Today, 2013, 8, 403-416.

66 E. Castillejos, R. Bacsa, A. Guerrero-Ruiz, I. RodriguezRamos, L. Datas and P. Serp, Nanoscale, 2011, 3, 929. 67 M. Haruta and M. Daté, Appl. Catal., A, 2001, 222, 427. 